\title{
UMBATRA
}

Indonesian Journal of Anthropology

Volume 5 (2) Desember 2020 || eISSN 2528-1569

pISSN 2528-2115 || http://jurnal.unpad.ac.id/umbara

DOI : 10.24198/umbara.v5i2.29720

\section{Warga Samin di Kudus dan Pelestarian Tradisi Budaya Jawa}

\author{
Moh Rosyid \\ Institut Agama Islam Negeri (IAIN) Kudus, Jawa Tengah \\ mrosyid72@yahoo.co.id
}

\begin{abstract}
This study aims at describing some of the Javanese cultural tradition that are preserved and neglected by the Samin (puritan Javanese community) in Kudus; and their reasons for doing so. Data of this study were collected through in-depth interview to Samin local leader and observation to the daily activities of the Samin. Data were analysed according to the principal of descriptive qualitative. The results of this study suggest that the Samin preserves some of Javanese traditions, such as own a sacred dagger (keris), gems, wearing black clothes, folk songs, gamelan and poetry. Keris usually owned by male leadersand they use it in healing, protecting the land, and serves as spiritual partner to the owner. Meanwhile, the Samin no longer preserve some other Javanese traditions; such as dance and arts; and raising buffalo and turtledove as livelihood due to limited resources. The Samin preserves their ancestral way of life and inherit it to their younger generation through oral tradition.
\end{abstract}

Keywords: samin, tradition, culture, Java, preservation

\begin{abstract}
Abstrak
Studi ini bertujuan menggambarkan tradisi dan budaya Jawa yang masih dilestarikan dan tidak lagi dilestarikan oleh warga Samin di Kudus serta alasannya. Warga Samin, selain memiliki identitas sebagai penganut ajaran Samin, mereka juga bagian dari etnis Jawa. Data dalam studi ini diperoleh melalui wawancara pada tokoh warga Samin dan observasi pada kehidupan keseharian warga Samin di Kudus, Jawa Tengah. Data dianalisis mengikuti prinsip analisis deskriptif kualitatif. Hasil studi ini menunjukkan bahwa beberapa tradisi budaya Jawa yang dilestarikan yaitu kepemilikan keris, batu berharga, pakaian khas berwarna hitam, seni kidungan, dan pepatah dari leluhur Samin. Keris hanya diwariskan kepada tokoh (botoh) lelaki dan digunakan sebagai media pengobatan, "penjaga" lahan sawah dari hama, mitra hidup batin, dan pengendali sombong. Ajaran lelulur dilestarikan oleh warga Samin melalui tradisi tutur, tidak tertulis. Tradisi dan budaya yang tidak dilestarikan adalah gamelan, tarian, dan pemeliharaan beberapa jenis hewan (perkutut dan kerbau). Gamelan tidak dilestarikan karena harganya mahal. Tari juga tidak dilestarikan karena tidak adanya media berlatih menari. Perkutut tidak dipelihara sebagai hobi, dan kerbau juga tidak dipelihara sebagai penghidupan karena tidak ada lahan.
\end{abstract}

Kata kunci: Samin, tradisi, budaya, Jawa, pelestarian 


\section{Pendahuluan}

Orang Samin merupakan para pengikut ajaran Ki Samin Surosentiko, seorang guru ilmu kebatinan. Ki Samin memulai ajarannya pada 1890 saat ia berusia 31 tahun di Plosowetan, Kabupaten Blora. Ajaran Samin bersumber dari Serat Punjer Kawitan, Serat Pikukuh Kasajaten, Serat Uri-Uri Pambudi, Serat Jati Sawit, dan Serat Lampahing Urip (Mukodi dan Burhanuddin, 2015:35).

Ajaran kebatinan Ki Samin disebarkan secara lisan dan diwarisi secara turun-menurun oleh pengikutnya. Inti ajaran Samin adalah tentang etika hidup; diantaranya ajaran tentang pantangan untuk memiliki sifat drengki (memfitnah), srei (serakah), panasten (mudah tersinggung atau membenci sesama), dawen (mendakwa tanpa bukti), kemeren (iri hati, ingin memiliki barang milik orang lain), nyiyo marang sepodo (berbuat nista pada sesama), dan bejok reyot iku dulure, waton menungso tur gelem di ndaku sedulur (menyia-nyiakan orang lain tak boleh, cacat seperti apapun, asal manusia adalah saudara jika mau dijadikan saudara).

Pada 1897, wilayah Ki Samin di Blora ditetapkan sebagai wilayah houtvesterijen oleh pemerintah Belanda. Aturan houtvesterijen ini membatasi akses rakyat pada sumber daya alam di hutan, diantaranya untuk mengambil kayu ${ }^{1}$. Ki Samin tidak menyetujui ketetapan itu dan berupaya melawan pemerintah Belanda tetapi gagal.

Pada 1916, Ki Samin bermigrasi ke Kudus setelah ia tidak berhasil memperluas ajarannya ke wilayah Tuban, Jawa Timur (Faturrohman, 2003:61). Ia pun kemudian menyebarluaskan ajarannya di Jawa Tengah. Para pengikut Ki Samin tersebar di wilayah Pati dan Kudus. Menurut Soerjanto (2003), orang Samin di Kudus berasal dari Desa Randublatung, Blora, ketika Ki Samin Surowijoyo dengan kitabnya singgah di Desa Kutuk, Kudus. Di Kudus, orang Samin terdiri atas beberapa kelompok, yaitu Sosar (dari Desa Kutuk, Undaan, Kudus), Radiwongso (dari Dukuh Kaliyoso, Karangrowo, Undaan, Kudus), dan Proyongaden (dari Desa Larekrejo,
Undaan, Kudus). Di Pati, orang Samin Pati bermukim di Desa Bombong, Kecamatan Sukolilo, Kabupaten Pati. Utomo (2013:190) menyebut bahwa ajaran Samin di Desa Baturejo, Pati berasal dari warga Dusun Kaliyoso, Desa Karangrowo, Undaan, Kudus keturunan Jambat. Namun, menurut catatan lain disebutkan bahwa keberadaan orang Samin di Pati justru hadir lebih dulu sebelum orang Samin di Kudus.

Orang Samin dapat dikelompokkan menjadi dua. Kelompok pertama adalah mereka yang masih mengikuti prinsip hidup seperti halnya di era Ki Samin Surosentiko yakni: (1) tidak sekolah formal, tetapi 'sekolah' di rumah dengan pendidik adalah orangtua dan sesepuhnya (botoh). Selain di rumah, pendidikan juga dilakukan pada forum pertemuan rutin berkala dalam lingkup internal warga Samin di Kudus. Materi yang diajarkan dalam sekolah itu adalah praktik kehidupan sebagaimana ajaran Samin yang diwariskan secara lisan; (2) kawin dengan sesama warga Samin dan tidak dicatatkan di lembaga negara, sehingga pasangan suami istri Samin tidak memiliki akta/ surat kawin dari Kantor Dinas Kependudukan dan Catatan Sipil (Dukcapil) Kabupaten Kudus. Penghulu pada perkawinan warga Samin adalah bapak dan ibu dari mempelai sendiri; (3) apabila warga Samin memiliki hajat mengawinkan atau mengkhitankan anak lelakinya, orang Samin mengundang saudara, tetangga, dan kerabat yang dikenal. Tamu diundang secara lisan dari rumah ke rumah. Tamu pantang memberi buah tangan atau menyumbang uang, sehingga kehadirannya hanya untuk menghadiri acara, tanpa memberi sesuatu apa pun.

Kelompok kedua adalah warga Samin yang sudah tidak lagi melaksanakan prinsip hidup seperti kelompok pertama. Mereka sudah bersekolah formal (sejak tahun 1970-an) dan banyak yang lulus SMK/SMA. Gaya hidup mereka pun juga lebih modern. Sejak 2019, perkawinan mereka dicatatkan di Kantor Dukcapil agar mendapat akta kawin dan agar tidak disebut kawin kumpul kebo, serta

${ }^{1}$ Pada 1918 semua hutan di Blora pun dijadikan sebagai area houtvesterijen oleh pemerintah Belanda (Ba'Asyin dan Ba'asyin, 2014:20). 
apabila bercerai (baik cerai hidup atau cerai mati), perempuan berhak mendapatkan harta warisan dari suami. Saat ini sudah terkumpul berkas dari 14 warga Samin yang status perkawinannya akan disahkan di Kantor Dukcapil Kudus.

Bagi warga Samin kelompok kedua ini, tamu yang diundang perkawinan atau sunatan diharapkan memberi sumbangan sembako (khususnya kalangan perempuan) dan uang (kalangan lelaki). Mereka berpenghidupan sebagai pekerja urban diantaranya sebagai pekerja bangunan. Diantara mereka ada yang kawin dengan nonSamin secara Islam. Mereka mengadopsi gaya hidup kekinian. Sebagian warga dari kelompok Samin ini bahkan memiliki rumah mewah, mobil, handphone bermerk, dan tidak lagi mengadopsi gaya hidup petani. Kelompok kedua ini, sulit dibedakan dengan warga non-Samin. Selain itu, mereka hobi berjejaring dengan LSM dan pegiat HAM. Mereka pun mulai mengajukan tuntutan atas hak mereka kepada negara, seperti penyediaan guru penghayat Samin di sekolah formal. Namun, tuntutan ini belum dapat dipenuhi karena memang belum ada warga Samin yang bergelar sarjana (yang menjadi syarat guru di sekolah formal).

Warga Samin kelompok pertama berkesempatan untuk mempertahankan ajaran leluhur mereka daripada kelompok kedua. Sebab, penghidupan mayoritas kelompok kedua tidak memungkinkan mereka menjalankan ajaran leluhur secara ketat karena harus merantau. Mereka pulang ke kampung halamannya rata-rata tiga bulan sekali. Hidup di rantau sebagai pekerja inilah yang membuat mereka mengadopsi beragam gaya hidup. Pemuda warga Samin dari kelompok kedua sudah terbiasa menggunakan handphone model terbaru, model cukur rambut, dan ornamen anak muda. Imbas lainnya, mereka kawin dengan muslim/muslimah dan menjadi penganut agama Islam.

Bagi warga Samin di Kudus yang tergabung dalam kelompok pertama, mereka masih sangat taat menjalankan lima pantangan dalam berinteraksi, yaitu bedok (menuduh), colong (mencuri), pethil (mengambil barang yang masih menyatu dengan alam atau masih melekat dengan sumber kehidupannya, misalnya sayur-mayur di ladang), jumput (mengambil barang yang menjadi komoditas di pasar misalnya beras, hewan piaraan, dan kebutuhan hidup lainnya), dan nemu wae ora keno (pantangan menemukan barang). Kelompok kedua justru lebih mudah menjadi pihak yang menuduh (bedok) pihak lain karena nafsu/emosinya ketika mendapat kritik dari publik akibat perilakunya yang tidak utuh lagi (tidak sebagaimana kelompok pertama).

Kehidupan warga Samin di Kudus mendapat simpati publik. Mereka dikenal sebagai komunitas yang santun, jujur, beretos kerja tinggi, dan penolong sesama. Namun, aspek santun 'dimangsa' oleh oknum warga Samin yang tidak mampu mengendalikan emosi sehingga timbul konflik internal di kalangan warga Samin sendiri. Salah satu buktinya adalah terjadinya kasus perceraian yang termasuk kejadian langka di kalangan warga Samin $^{2}$.

Selain memperoleh simpati dari warga Kudus, warga Samin juga mendapat stigma sebagai pembangkang. Hal ini akibat perilaku warga Samin di Kudus yang menghalangi pembangunan irigasi untuk lahan persawahan publik pada tahun 1985-an. Perlawanan sebagian warga Samin dipicu oleh pelaksanaan pengerukan lahan/tanah sawah yang tidak sesuai kesepakatan. Hasil pengerukan digunakan untuk dua tanggul di sisi kanan dan kiri, sedangkan di tengah dua

\footnotetext{
${ }^{2}$ Jumlah perceraian tergolong rendah karena penulis yang meneliti Samin di Kudus sejak tahun 2008 hingga kini, menemukan bahwa perceraian di Samin hanya terjadi satu kali. Akan tetapi, perceraian tersebut tanpa adanya campur tangan dari keluarga perempuan (Dwi) yang menyerahkan menantunya (Anteng) pada keluarga Anteng. Lazimnya apabila terjadi perceraian Samin, kedua belah pihak (antar-keluarga perempuan dengan lelaki menyerahkan dengan baik-baik disertai alasan cerai). Hal ini mengundang respon negatif publik (Samin dan Samin). Terjadinya perceraian akibat emosi yang tidak terkendali oleh bapak dari Dwi, membuat Anteng harus bercerai tahun 2016. Kejadian tersebut menyebabkan interaksi keluarga Anteng dan keluarga Samin lainnya menjauh dengan kelompok keluarga Dwi hingga kini. Hal ini berimbas pada munculnya citra negatif dari warga Samin lain dan non-Samin, yakni temperamental dalam menggugurkan kehidupan keluarga Dwi dengan Anteng di Desa Larekrejo, Kecamatan Undaan, Kudus.
} 
sisi tanggul digunakan untuk irigasi baru. Warga non-Samin tidak berani menentang pembangunan tersebut karena pada era Orde Baru, 'kekuasaan' tidak dapat dikendalikan oleh pihak mana pun, meskipun melanggar kesepakatan dengan warga.

Warga Samin adalah pewaris ideologi Saminisme, dan bukan generasi biologis Ki Samin. Artinya, orang menjadi warga Samin karena mengikuti ajaran Samin, bukan karena keturunan atau bukan faktor dari keluarga trah Samin. Selain sebagai pengikut ajaran Samin, warga Samin di Kudus, Jawa Tengah adalah bagian dari etnis Jawa. Mereka memiliki kekhasan yakni apabila mengadakan acara khusus seperti perkawinan, mereka mengenakan baju khas yakni warna hitam, memakai iket kepala, baju sruwal, celana tokong (panjangnya hingga di atas mata kaki) bagi lelaki, dan kebaya bagi perempuan. Warga Samin mengaku beragama Adam (oleh pemerintah dikategorikan penghayat kepercayaan). Identitas warga Samin yang tidak tunggal ini menarik untuk dikaji. Studi ini menggambarkan upaya pelestarian budaya khas dan simbol budaya khas Jawa oleh warga Samin di Kudus.

\section{Kajian Pustaka}

Kata simbol berasal dari bahasa Yunani symbolos, berarti tanda atau ciri yang memberitahukan sesuatu atau keadaan yang diberitahukan subjek kepada objek. Simbol, dengan demikian, bermakna lambang, kembang, sinamuning samudra atau yang tersembunyi dalam kiasan seperti tanggap ingsasmita (dapat menangkap makna yang tersembunyi) (Herusatoto, 2000:10). Simbol atau lambang bermakna perwujudan aspek budaya yang memunculkan hasil penafsiran oleh pelaku budaya yang diwujudkan dalam bentuk benda/barang, pernik, aroma, sebutan, doa, dan lainnya yang disimbolkan. Penuangan simbol berupa penyerupaan, perwujudan identitas, dan lainnya yang substansi maknanya mendalam. Di dalam konteks aplikatif, simbol juga bermakna doa. Sebagaimana ritual dan seremoni slametan yang disisipi kuliner beraroma doa, seperti slametan kehamilan menyertakan pisang raja, pisang emas, dan lainnya, yang bermakna (doa) agar anak menjadi luhur dan pandai.
Namun, makna yang terkandung jika tidak dibuka lebar, dikhawatirkan akan kehilangan makna, bahkan terjadinya pergeseran secara frontal terhadap bentuk budaya. Misalnya, tradisi slametan bagi masyarakat Jawa sebagian telah diubah bentuk dan model kuliner yang disajikan, seperti penghilangan kuliner tradisional dengan kuliner masa kini (roti atau kue modern) karena tidak memahami makna yang terkandung dalam kuliner tradisional atau karena lebih mengedepankan aspek praktis. Solusinya, perlu dibuka dialog terhadap makna budaya yang disimbolkan karena simbol budaya berpeluang multiinterpretatif dan subjektifitasnya (keragaman) pun sangat tinggi bagi pelaku budaya yang berasal dari intern komunitasnya, apalagi ekstern komunitas budayanya.

Kajian tentang simbol budaya tertuang dalam dimensi budaya. Dimensi ini terdiri atas kognitif, evaluatif, dan simbolik. Dimensi simbolik dijadikan media interaksi manusia yang disimbolkan dalam berbudaya (Endraswara, 2005:22). Simbol diaplikasikan dalam ungkapan pelaku budaya untuk merespon kehidupannya yang disimbolkan. Orang Jawa memiliki beberapa bentuk simbol, seperti keris, perkutut, upacara ritual, dan seremonial. Hal tersebut berasal dari lingkungan sehari-hari. Dimensi budaya yang didukung pemilik budaya dan difasilitasi pemerintah bersama masyarakatnya membentuk identitas (identity). Identitas mengandung arti membuat sesuatu menjadi identik (diidentikkan) atau sama (disamakan) atau diserupakan dengan yang lain, mengakui keberadaan sesuatu yang dibanggakan, dirasakan, dilihat, diketahui, digambarkan, diklaim, dan dijustifikasi karena adanya kesamaan atau penyerupaan. Dengan demikian, identitas budaya adalah karakter atau ciri kebudayaan bagi sekelompok orang yang diketahui batas-batasnya.

Simbol budaya dan tradisi yang masih dipegang teguh (dikukuhi) sebagian etnis Jawa, diantaranya (1) benda (rumah, pakaian dan aksesorisnya, karya seni, keris, akik, dan gamelan); (2) hewan (burung perkutut dan kerbau); (3) sebutan yang menyatakan kebesaran Tuhan; (4) warna khas; (5) pepatah; (6) suara/musik; dan (7) gerakan/tari. 
Pertama, benda yaitu (1) pakaian (baju dan sarung Jawa) berupa baju berlengan panjang, identik dengan warna hitam dengan kain lembaran dan sarung yang cara memakainya dilipatkan, identik dengan kerapian atau ketundukan; (2) aksesori pakaian (blangkon) identik dengan pakaian 'bawahan' yang loyal (bekti lan mituhu) kepada pimpinannya (ndoronya). Aksesoris pakaian ini dipakai di lingkungan kerajaan Jawa, dalang beserta pemusiknya, pakaian kemanten model Jawa beserta 'punggowonya'; (3) aplikasi dalam karya seni seperti bertato ${ }^{3}$, misalnya patung atau hasil ukiran; sebagaimana kepercayaan sebagian etnis Cina dan Jawa untuk penunggu rumah, Anjing $\mathrm{Fu}$, yang diwujudkan dalam patung singa. Jika anjingnya jantan diletakkan di sebelah kiri pintu, jika betina diletakkan di sebelah kanan pintu rumah; (4) akik, merupakan benda yang menempel dalam cincin, biasanya sejenis batu. Akik pun berfungsi sebagaimana keris. Namun, terdapat perbedaan mendasar bahwa akik tidak untuk senjata perang; (5) rumah adat, seperti di Kudus, Jawa Tengah; (6) gamelan, sebuah kekhasan musik tradisional Jawa yang mengiringi pentas seni berupa (khususnya) wayang kulit. Peran gamelan sebagai 'suara khas' yang bernilai seni (musik) tinggi menjadi simbol kecintaan masyarakat Jawa terhadap musik. Gamelan merupakan alat musik jenis perkusi yang terbuat dari besi, perunggu atau gangsa (percampuran antara timah dan tembaga). Seperangkat gamelan terdiri dari kendhang, bedhug, kempul, gong, beri, kethuk, kenong, gambang, gender, rebab, suling, siter, bonang, slenthem, demung, saron, peking, dan kemanak, minimal dimainkan oleh 18 pradangga (pemusik) dengan penyanyi tunggal (waranggana); (7) keris, senjata tikam khas Indonesia, benda tosan aji yang terbuat dari campuran antara besi kotor, besi bersih, pamor, lapisan pamor, dan metal berbentuk lekuk, (dianggap) sebagai pusaka. Menurut Linus, keris berfungsi sebagai wadah wahyu dan untuk mantra (Suryadi, 1993:43), benda bertuah, barang antik, bernilai isoteris yakni kekuatan supranatural. Keris memiliki tata pembuatan dengan penguasaan teknik tinggi, artistik, dan daya magis. Bagian keris meliputi gagang, batang, dan sarung (warangka). Warangka terbuat dari kayu jenis cendana wangi yang menambah kekuatan gaib, kayu asem Jawa yang terdapat teras (galih) menambah kekuatan, kayu kebak untuk meredam kekuatan jahat dalam keris, dan kayu awar-awar (Hajid, 2005:98). Sebagian keris yang bertuah dan dijadikan senjata juga berfungsi sebagai media kanuragan. Menurut Empu Jeno Hanumbrojo keris diklasifikasikan menjadi tayuhan yang proses pembuatannya didahului tapa brata si empu dan keris sovenir yakni tanpa tapa brata, meskipun kepemilikan hanya terbatas pada kalangan tertentu.

Kedua, hewan seperti kerbau, pedet (anak sapi), burung perkutut ${ }^{4}$. Pengeramatan kerbau Kiai Slamet di Keraton Kasunan Surakarta Hadiningrat yang dimanfaatkan pembuka (cucuk lampah) jalan untuk kirab malam 1 Sura (1 Muharram) sebagai lambang keselamatan. Pada awal Kerajaan Mataram, pusaka dan kerbau Kiai Slamet dikeluarkan hanya jika terjadi wabah penyakit (pagebluk) dan bencana alam, sebagaimana semasa Paku Buwono XII yang mengadakan kirab setiap minggu (Kamis malam) karena adanya bencana alam. Pada tahun 1970, kirab tersebut ditiadakan karena persepsi masyarakat terhadap keraton yang berubah. Pada tahun 1972, pemerintah Orde Baru memerintahkan Keraton Surakarta

\footnotetext{
${ }^{3}$ Sebagian warga (terutama kaum muda) menyimbolkan karya seni berbentuk tato dengan beberapa argumen versi Masyarakat Bertato (Masberto) (i) pernyataan seni untuk kehidupan atau penanda diri yang dibuat dengan memasukkan pigmen mikro ke dalam kulit, (ii) merupakan salah satu bentuk modifikasi tubuh atau ideologi yang mengutamakan tubuh dalam memperoleh makna hidup, (iii) semacam ideologi yang mengutamakan tubuh dalam memeroleh makna hidup, dan (iv) seni merasakan nikmatnya 'nasgitel' \{panas, legi (manis), kentel (kental)\}, hal tersebut tidak dapat dijelaskan dengan lugas, hanya dapat dirasakan (dalam batin). Menurut Ady Rosa (Universitas Negeri Padang) tradisi menato tubuh tertua di dunia pada masyarakat Mentawai, Sumbar sejak tahun 1.500 SM atau 200 tahun lebih dulu dari pada Mesir, sedangkan tradisi tato di Siberia sejak tahun 300 SM. Tradisi mentato di Mentawai sekarang semakin pudar, meskipun pada masa lalu diwajibkan bagi yang berusia dewasa. Solusi mengeksiskannya adalah penyelamatan motif.

${ }^{4}$ Konteks non-Jawa dikenal banteng sebagai ritual dan festival San Fermin diikuti ribuan peserta. Pesta tahunan warga Pamplona, Spanyol yakni adu dikejar banteng sejak tahun 1924.
} 
menghidupkan kembali kirab, sehingga akhirnya dilanggengkan setiap tanggal 1 Sura. Pusaka dan kerbau tersebut dianalogikan dengan tongkat Nabi Musa yang membuka laut dan menenggelamkan Firaun.

Potensi burung perkutut terpilah dua yakni memiliki yoni dan kosong (yoni) dengan potensi manggung suara akhir koong. Yoni dianggap mampu mendapatkan kesejahteraan ekonomi, wibawa, menggaet perempuan, dan perlindungan bagi si empunya. Indikator perkutut yang beryoni adalah nyekukruk, kotorannya tampak tidak sehat (karena kemasukan yoni atau ditinggalkan yoni). Perkutut memiliki kepraktisan karena makanannya relatif mudah dan irit, kotoran dan bangkainya tidak (terlalu) berbau, umurnya (lebih) panjang, jinak, dan harganya mahal (Suryadi, 1993:117). Namun, pasca wabah penyakit flu burung, pasaran (harga) jenis burung perkutut terpuruk karena diduga penyebab penyebar virus; atau sebaliknya jumlah burung perkutut yang mengalami penurunan karena terserang flu burung menyebabkan harga (diduga) melambung tinggi. Dalam konteks masa kini, potensi burung berdaya beli tinggi karena memiliki kemampuan antara 'manggung' atau 'ngoceh', biasanya benda yang diagungkan memiliki tuah. Menurut Anan, tuah bermakna manfaat atau kegunaan yang berhubungan dengan hal gaib yang mengisi sesuatu objek; sehingga yang bertuah terdapat dalam (a) benda yang dijadikan tempat penyimpanan tuah, (b) isi yakni kekuatan yang berupa jin, khodam, dan yang sejenis, dan (c) manfaat yakni kekuatan yang berasal dari benda bertuah (Hajid, 2005:92).

Ketiga, sebutan yang menyatakan kebesaran sebagai wujud tunduk dan ngabekti, seperti Gusti (Gusti Allah, Gusti Kang Maha Agung, Gusti Kang Murbeng Dumadi, Gusti Kang Angakaryo Jagat) dan Pangeran (Pangeran Kang Maha Tunggal). Keempat, warna dan pewarnaan memiliki makna simbolik, seperti hitam yang identik dengan konsistensi, kuning dengan duka, merah keberanian, hijau keramahan, dan biru kelembutan. Dalam menafsirkan simbol tersebut, terdapat perbedaan makna antar daerah karena tidak mempunyai pola pemahaman yang sama.
Kelima, pepatah, seperti sepi ing pamrih rame ing gawe, jagad ora mung sak godong kelor, sopo gawe nganggo, sopo nandur ngunduh, ngono yo ngono nanging mbok yo ojo ngono, surodiro jayaningrat lebur dening pangastuti, sadumuk bathuk sanyari bumi, rawe-rawe rantas malang-malang putung holopis kuntul baris dan masih banyak lagi. Pepatah tersebut menegaskan semangat jiwa, petuah, atau sindiran halus. Keenam, suara atau musik, sebagaimana musik tradisional khas Gunung Kidul, DIY yakni Rinding sejak era Majapahit. Alat musik tiup ini terbuat dari bambu berbentuk pipih persegi panjang, di permukaannya dibuat lubang yang menghasilkan bunyi berbentuk cawang dengan ukuran $5 \times 20 \mathrm{~cm}$ dan $4 \times 15 \mathrm{~cm}$. Alat musik tersebut dipercaya sebagai ritual tahunan musim panen dan simbol penghormatan kepada Dewi Sri, penganugerah padi. Berdasarkan sejarahnya, Rara Resmi, isteri selir Raja Majapahit, Brawijaya, menjelang runtuhnya Majapahit melarikan diri bersama dua putranya, Gading Mas dan Onggocolo, kemudian singgah di Wonosadi, Gunung Kidul dan berbaur dengan masyarakat. Gading Mas menekuni ilmu kanuragan, sedangkan Onggocolo menekuni seni dan menemukan musik rinding ketika bertapa di tengah hutan Wonosadi. Musik tersebut masih lestari di wilayah Sidorejo, Beji, Ngawen, dan Gunung Kidul.

Ketujuh, gerakan atau tari, seperti tari angguk (tarian baris-berbaris) yang eksis di Grobogan, Jawa Tengah; adapun di Purworejo dan Gunung Kidul menyebutnya sebagai tari dolalak. Tari ini menyimbolkan gerakan sebagai ungkapan syukur dan kepatuhan pada Yang Kuasa. Tari yang mementaskan 13 penari (atau berjumlah ganjil) ini sudah ada sejak era penjajah Belanda. Nyanyian dan gerakan tari dasar (sayatabe, musaleya, albe, dan ongket-ongket) didukung alat musik berupa jedor, terbang, kendang, harmonika, dan tamborin (kinciran). Namun, karena minimnya panggilan pertunjukan, nasib tarian ini memprihatinkan. Menurut Suryadi (1993:106), seorang lelaki Jawa dianggap lengkap dengan jerih payahnya apabila mempunyai wismo (rumah), wanito (isteri), curigo (keris), turanggo (kuda; media transportasi), dan kukilo. 


\section{Metode}

Studi ini dilakukan secara kualitatif dengan desain studi kasus. Pengumpulan data dilakukan pada 2019 melalui wawancara dengan botoh (tokoh) dan warga Samin di Desa Larekrejo, Kecamatan Undaan, Kabupaten Kudus, Jawa Tengah. Informan tunggal dalam studi ini adalah Budi Santoso. Ia menjadi satu-satunya sumber data yang mumpuni. Ia merupakan warga Samin yang pertama kali lulus sekolah dasar (SD) tahun 1970 dan lulus kejar paket B tahun 2016. Warga Samin seusia Budi umumnya tidak sekolah formal karena kondisi perekonomian keluarga warga Samin yang belum sejahtera. Anak perjaka biasanya membantu orangtuanya menjadi buruh tani. Hal ini berbeda dengan Budi Santoso yang berasal dari kategori keluarga mampu. Orang tuanya memiliki sawah yang luas. Ketokohan Budi pun sangat penting bagi warga Samin karena berperan sebagai tempat bertanya apabila warga Samin menghadapi problema kehidupan. Budi juga menjadi juru sembuh apabila warga Samin dan non-Samin meminta pertolongan pengobatan tradisional tatkala menderita sakit ringan, seperti demam yang tinggi, kesurupan, dan sejenisnya. Ketokohannya mewarisi dari orangtuanya, mendiang Sumarsono. Selain wawancara, data juga dikumpulkan melalui observasi di lingkungan Samin di Desa Larekrejo, Kecamatan Undaan, Kudus; dan telaah literatur tentang Samin. Data dianalisis dengan pendekatan deskriptif kualitatif.

\section{Hasil dan Pembahasan}

Simbol pada masyarakat Jawa yang masih dipegang teguh (dikukuhi) sebagian etnis Jawa, antara lain adalah, (1) benda (rumah, pakaian dan aksesorinya, karya seni, keris, akik, dan gamelan), (2) hewan (burung perkutut dan kerbau), (3) sebutan yang menyatakan kebesaran Tuhan, (4) warna khas, (5) pepatah, (6) suara/ musik,dan (7) gerakan/tari. Diantara ketujuh karya budaya Jawa yang masih dilestarikan oleh sebagian warga Samin di Kudus adalah 1) pakaian, 2) keris (hanya bagi tokoh Samin), 3) pepatah, dan 4) karya seni suara (kidungan).
Pakaian tradisional warga Samin disebut baju sruwal dan celana tokong. Baju ini tanpa kerah leher, panjang lengannya tidak sampai pergelangan tangan, dan tidak terdapat kancing baju di lengannya. Celana tokong memiliki panjang tidak sampai mata kaki, bentuknya silinder, dan tidak berkancing. Warna khas untuk klambi sruwal dan celana tokong adalah hitam. Baju ini dikenakan untuk menghadiri forum tertentu, misalnya upacara perkawinan warga Samin, melayat kematian warga Samin, dan menghadiri undangan aparat pemerintahan. Apabila warga Samin beraktifitas sehari-hari dan bekerja, mereka berpakaian lazimnya warga non-Samin.

Warga Samin memiliki pepatah yang mereka warisi dari leluhurnya seperti, (a) Sedulur sikep kudu iso nglakoni ngalah, gunem sekecap tutuke pangan secokotan (orang Samin harus melakukan sikap mengalah, apabila berbicara secukupnya dan makan pun ala kadarnya); (b) Barang apik nak iso ora kanggo dewe (hal kebaikan tidak untuk dirinya sendiri); (c) Gunemem iki, sak iki mbok dol sewu ora payu. Mbesok, mbok dol sekethi ora ngedoli. Kuwe mbesok diluru dulur (ajaran Samin, kini (masa Ki Samin) dijual seharga Rp 1.000 tidak laku, besok, dijual mahal, banyak yang berminat. Kamu nanti dicari orang untuk dijadikan saudara); (d) Ora seneng digunggung, Ora serek diolo (tidak suka dipuja, tidak benci dicerca); (e) Tindak sepecak, gunem sekecap, ojo ngumbar suoro, ojo ngumar tatanan, ojo ngumbar karep (berjalan setahap, berbicara secukupnya, tidak sombong dalam berbicara, jangan melanggar aturan Samin, jangan melepas keinginan); (f) Seneng nyandang, doyan mangan, kudu toto gauto gebyah macul biyen yo saiki ngantiyo mbesok, yo ajek seng te-e dewe (suka berpakaian, suka makan, harus bekerja, mencangkul lahan milik sendiri sejak dulu dan yang akan datang); (g) Sebab dalane bener utowo luput ono loro, pengucap lan kelakuan, sopo ngaku kuwi sopo, lan kuwi opo, sopo wonge, opo agamane, yen tumindak lan pengucape ora bener, yo mesti salah (penyebab salah atau benarnya orang 
karena dua hal yakni ucapan dan perbuatan); (h) Lung tinulung, lak jinalak, tang piutang, dono weweh iku wes anggone wong urip, sing sopo iso ninggal iku, mulo menungso kudu jejer karo sepadane (saling menolong, saling memberi, saling berhutang, saling memberi itu menjadi kelaziman untuk menyadari); (i) Sepi ing pamrih rame ing gawe (ikhlas dalam berkarya); (j) jagad ora mung sak godong kelor, sopo gawe nganggo, sopo nandur ngunduh, ngono yo ngono nanging mbok ojo yo ngono, surodiro jayaningrat lebur dening pangestuti (dunia ini tidak selebar daun kelor, siapa yang membuat bertanggung jawab, siapa yang menanam akan menuai); (k) sadumuk bathuk sanyari bumi, rawe-rawe rantas malang-malang putung, holopis kunthul baris (semangat dan nasionalisme) (Rosyid, 2011). ${ }^{5}$

Seni suara (kidungan) masih dilakukan oleh warga Samin dengan ekonomi mampu. Misal, ketika mereka memiliki hajat seperti mengkhitankan anak lelakinya, mereka mengundang grup wayang kulit. Selain itu, mereka juga mengundang pengidung (seni suara khas Jawa), bahkan warga Samin yang mampu mendendangkan/menyanyikan kidung juga ikut serta mengidung (mendendangkan seni kidung).

Suryadi (1993:54) mengatakan keris merupakan karya fenomenal. Sebagian keris yang bertuah adakalanya dijadikan sebagai 'senjata' dan memiliki daya kanuragan. Kepemilikan hanya terbatas pada kalangan tertentu karena memiliki tata pembuatan dengan penguasaan teknik tinggi, artistik, dan daya magis.

Keris merupakan senjata tikam khas Indonesia sebagai benda tosan aji dan pusaka yang terbuat dari campuran besi kotor, besi bersih, pamor, lapisan pamor, dan metal berbentuk lekuk. Bahan utamanya dapat berupa besi sekitar 8 s.d $10 \mathrm{~kg}$, dipijar dan ditempa hingga hilang percikan pijarnya menjadi lempengan yang dilapisi sekitar $1 \mathrm{s.d} 2 \mathrm{~kg}$ baja untuk ketajaman, dilapisi batu meteor dari luar angkasa sekitar 0,5 s.d $1 \mathrm{~kg}$. Ketiga bahan tersebut ditempa dan dilipat (diiringi doa) ratusan kali hingga tersisa $1 \mathrm{~kg}$. Menurut Suryadi, keris berfungsi sebagai, (1) wadah wahyu dan untuk mantra; (2) sebagai benda bertuah, sebagian keris yang bertuah dan dijadikan 'senjata'; dan (3) media kanuragan. Keris dapat diklasifikasikan menjadi keris tayuhan proses pembuatannya didahului tapa brata si empu dan keris sovenir yakni tanpa tapa brata, meskipun kepemilikan hanya terbatas pada kalangan tertentu.

Keluarga yang mapan menjadikan keris sebagai aksesori dan penanda identitas. Selain itu, keris juga menjadi media pengasihan atau penglarisan barang dagangan, seperti keris berpamor ganjur yang bentuknya menyerupai gambar pager gunung, berfungsi sebagai pelaris hasil peternakan. Kepemilikan keris tidak selalu terpublikasi karena muatan tuahnya.

Keris diperoleh melalui pewarisan, hadiah, hubungan guru-murid, pembelian, keberuntungan (menemukan), dan pertolongan ahli (Suryadi, 1993:26). Keris dibuat oleh tiga peran yakni, етрu (dari bahan mentah hingga jadi), mranggi (pembuatan warangka dan bahan pegangan keris), dan gemblak/kemasan (pembuat kemasan keris) (Suryadi, 1993:87). Pada era kerajaan di Jawa, pembuat keris (empu) menduduki posisi penting jika terjadi perang untuk menyediakan senjata, seperti tumbak, trisula, patrem, panah cemeti, kudi, dsb. Nama empu antara lain Supodriyo (era Kerajaan Majapahit), Jokosupo/Sedayu (Majapahit), Supoanom (Tuban), Sektilanang (Tuban), Ny. Panjang Emas (Mataram), Cindeamoh (Mataram), Suponyang (Mataram), Entowayang (Kartasura), Mas Ayu Kadarsih/ Hangabei (Kartasura), R.A Pandit (Surakarta), Ny. Badur (Ngentho-Entho, Yogya), Kertoyudo (Ngentho/Entho, Yogyakarta), Joyosemito (Jenggalan), Joiruno (Jenggalan), Supowinangun (Jenggalan) (Suryadi, 1993:65). Warga Samin di Kudus juga mengenal beberapa nama empu yakni Mpu Gapuk, Gandreng, Supo Madurangin, dan Suwarno. Proses membuat keris melalui lelaku berupa puasa atau semedi

\footnotetext{
${ }^{5}$ Sebagai perbandingan, pepatah masyarakat Baduy, Pondok teu meunang disambung, nu panjang teu meunang dipotong (yang pendek tak boleh disambung dan yang panjang tak boleh dipotong). Maknanya, orang Baduy pada dasarnya menerima alam sebagaimana adanya.
} 
untuk mendapatkan ilham dari Yang Maha Kuasa. Adapun kemampuan keris terbagi menjadi kemampuan fisik (menyimpan racun, untuk kekerasan, dan keseimbangan) dan kemampuan spiritual berupa aura yakni energi yang memancar dari benda/keris. Cara merawat keris bisa dengan mengoleskan minyak melati atau zakfaron secara berkala agar terlindungi dari karat (Hajid, 2005:108).

Keris sebagai karya budaya dimiliki orang tertentu dari berbagai agama dan suku di Indonesia. Bagi warga Samin yang bersuku Jawa, keris disebut gaman yang difungsikan ketika kebutuhan hidupnya didesak oleh kondisi, tidak untuk membela diri dari serangan lawan, tapi menjadi 'teman' membantu keperluan hidup. Pentingnya fungsi keris membuatnya diwariskan lintas generasi. Tekniknya melalui 'dialog' secara magis yang diawali dengan berdoa secara Samin (dirapal): Yang bumi aji jaman, aku arep tekok wesi aji (Wahai Yang Maha Kuasa, aku akan bertanya pada keris).

Fungsi, nama, dan manfaat keris pada warga Samin di Kudus, berbeda dengan fungsi keris lainnya. Pertama, Keris Remeng awalnya dimiliki Menak yang diwariskan pada anaknya, Suronggono. Fungsi keris ini menjaga harta supaya tidak dicuri, seperti 'menunggu' secara nonfisik di persawahan supaya tanamannya tidak dimangsa hama atau dicuri. Keris tersebut 'diajak berkomunikasi' agar auranya menunggu sawah, meski tetap disimpan di rumah. Kedua, Keris Jalak yang berfungsi memperlancar proses melahirkan bagi ibu. Keris ini awalnya dimiliki Modiwongso lalu diwarisi Radiwongso, berikutnya diwarisi Sukelan dan Sumarsono. Hingga kini, keris tersebut disimpan oleh pewaris Sumar di Kudus. Ketiga, Keris Kiai Pleret yang berfungsi dalam pengobatan penyakit ringan, misalnya influenza dan yang serupa. Pengobatannya dengan 'dialog' agar aura kerisnya menyembuhkan secara magis. Keempat, Keris Jangkung untuk prasarana sumber ekonomi, jalan keselamatan, dan meredam konflik. Keris tersebut kini diwarisi anak Sumar, Sudarmo. Salah satu pengalaman spiritualnya dengan Keris Jangkung yakni ketika anaknya akan bekerja bangunan di Jakarta pasca-musim tanam padi. Sebelum melepas putranya, Sudarmo berkomunikasi dengan keris, "Anakku kang aran Joko arep menyang Jakarta kerjo. Yen harapane apik, semeleho ing tangan tengenku. Ono dene ora apik semeleho ing tangan kiwoku" (Anakku, Joko, akan merantau ke Jakarta, bila hasilnya baik, beri 'sinyal', selanjutnya keris bersandar di lengan kanan tangannya. Tetapi, apabila prospek tidak sukses, bersandarlah di lengan tangan kiriku). Hasilnya, keris kala itu bersandar di lengan tangan kanan. Terbukti saat pulang kerja bangunan dari Jakarta, Joko membawa hasil kerja sesuai yang diharapkan (selama menunggu panen). Keberhasilan tersebut tidak terwujud tatkala saat pascapanen (menjelang musim menanam palawija), Sudarmo menanyakan, "bagaimana prospek panennya nanti bila kini menanam jagung?" secara perlahan, keris menyandar pada lengan tangan kirinya (sebagai penanda buruk). Sudarmo kurang yakin jawaban kerisnya maka ia bertanya lagi, keris pun tetap bersandar di lengan tangan kirinya. Namun, Sudarmo tetap menanam jagung dan terbukti panennya tidak optimal. Berbeda dengan fakta berikut, ketika di desanya ada konflik antar dua kampung (warga non-Samin), Sudarmo bertanya pada keris "opo mengko bengi kelompok wetan bergerakmenyerang kelompok kulon?" (Apakah nanti malam kelompok timur akan bergerak menyerang kelompok barat?), keris bersandar di lengan kirinya. Hal ini sebagai tanda tidak ada perlawanan dan terbukti. Kelima, Keris Ki Sombro yang berfungsi menghalau hama. Keenam, Keris Wengkang Jagad fungsinya untuk membantu pertanian. Ketujuh, Keris Gati Semarangan yang juga berfungsi di pertanian. Keris tersebut berasal dari Ramidin yang diberikan oleh Sumarsono, dan diwariskan kepada Budi Santoso (anak Sumarsono). Kedelapan, Keris Kiai Konang yang fungsinya belum diperoleh info penulis dan milik warga Samin di Kudus (Rosyid, 2019).

Keberadaan keris bagai hewan peliharaan yang membutuhkan pemeliharaan dengan cara diwarang (dicuci) tiap Sura (penanggalan 
Jawa). Caranya, kerisdirendam selama 30 hari (sebulan) dengan air kelapa dan potongan tumbuhan jenis lompong. Setelah bulan Sura, keris diambil dari media perendaman, dibersihkan, lalu disarungkan pada tempat semula. Keris akan memiliki tuah apabila pemiliknya tirakatan (berpuasa) selama 40 hari atau 7 hari, atau 3 hari atau puasa sehari semalam (tanpa makan dan minum).

Keris juga mempunyai daya ekstra, contohnya ketika keris milik Sumarsono diambil pencuri saat digunakan dalam 'memfasilitasi' kelahiran dari anaknya yang pertama di rumah. Tetapi, pada tahun berikutnya, keris dapat kembali di rumahnya. Leluhur Samin membekali pesan batin untuk mengendalikan emosi pemilik keris dengan pesan: Wong iku yeng menang yoiku yeng jujur, ora kerono wesi aji (orang menang apabila jujur, tidak karena memiliki keris). Hal ini agar pemilik keris tidak sombong.

Kepemilikan keris oleh tokoh Samin galibnya diwariskan oleh leluhur Samin pada keturunannya atas dasar 'persetujuan' keris dengan proses berdialog serta dengan pola interaksi melalui mimpi. Warga Samin hanya mewarisi keris dari leluhur secara regenerasi, seperti Sumarsono yang mendapat keris secara berurutan dari generasi atas Modiwongso, Radiwongso, hingga generasi bawah Sukelan (semuanya sesepuh Samin). Sumarsono mewariskannya pada anaknya yang lelaki karena dianggap mumpuni menerima warisan. Hal ini diawali 'persetujuan' keris dengan dialog magis atau melalui mimpi. Penulis belum mendapatkan data terkait warga Samin non-botoh yang memiliki keris dan pewarisan keris pada anak perempuan karena ketidakmudahan merawat keris. Penyebabnya karena pemilik keris merahasiakannya.

Simbol budaya yang tidak lagi dilestarikan di kalangan warga Samin adalah seni musik gamelan. Hal ini disebabkan oleh mahalnya harga seperangkat gamelan dan tokoh Samin tidak mampu memainkan gamelan. Di lingkungan Samin pun tidak ada yang memiliki alat musik tersebut. Hal tersebut berbeda dengan riset Subarkah (2017:115), bahwa Samin di
Pati masih mempertahankan untuk tidak berdagang dan perkawinannya tetap monogami. Selain itu menurut Ismail (2012:116), warga Samin tidak sekolah formal karena adanya anggapan kelas elit (bendara) sebagai antek Belanda dan tidak menjadi rakyat (kawula). Faktor ini berkaitan dengan semangat konfrontasi pada Belanda dan wujud sikap egaliter Samin; sedangkan, Samiyono (2010:86) mengatakan bahwa komunitas Samin di Pati memiliki identitas berupa pola permukimannya mengelompok, pakaian khas pada acara tertentu, berbahasa kiratabasa, tidak sekolah formal, dan menjadi petani. Dengan demikian, Samin di Kudus dan Pati memiliki perbedaan mendasar dalam kehidupannya.

\section{Simpulan}

Simbol budaya pada masyarakat Jawa yang masih dipegang teguh (dikukuhi) sebagian etnis Jawa berupa, (1) benda (rumah, pakaian dan aksesorinya, karya seni, keris, akik, dan gamelan, (2) hewan (burung perkutut dan kerbau), (3) sebutan yang menyatakan kebesaran Tuhan, (4) warna khas, (5) pepatah, (6) suara atau musik, dan (7) gerakan atau tari. Ketujuh karya budaya tersebut yang masih dipegang teguh sebagian warga Samin di Kudus adalah pakaian khas Samin yakni sruwal (baju) dan celana tokong yang berwarna hitam, pepatah dari leluhur Samin, seni suara (kidungan), dan keris (keris hanya bagi tokoh Samin); adapun yang tidak dilestarikan warga Samin di Kudus adalah seni tari dan memelihara hewan (burung perkutut dan kerbau). Sebagian warga Samin masih ada yang tetap memelihara burung perkutut, namun hanya sekedar hobi, bukan karena makna dari mitos burung. Tradisi menari sudah tidak dilestarikan karena tidak ada pihak yang mampu melatih dan sanggar berlatih tari jauh dari domisili warga Samin. Pemeliharaan kerbau tidak lagi dilestarikan karena warga tidak memiliki lahan untuk merawatnya. Kerbau membutuhkan kandang dan lahan untuk mandi dan menggembala di Padang rumput yang sudah tidak tersedia di lingkungan Samin. Lahan-lahan yang dibutuhkan tersebut dialihkan untuk pertanian padi pada musim tanam perdana dan kedua, sedangkan tanam ketiga untuk palawija. 


\section{Daftar Pustaka}

Ba'Asyin, A. S., dan Ba'asyin, M. A. (2014). Samin: Mistisisme Petani di Tengah Pergolakan. Semarang: Gigih Pustaka Mandiri.

Endraswara, S. (2005). Tradisi Lisan Jawa: Warisan Abadi Budaya Leluhur. Narasi.

Faturrohman, D. (2003). Hubungan Pemerintah dengan Komunitas Samin. Dalam Agama Tradisional: Potret Hidup Masyarakat Samin dan Tengger. Yogyakarta: LKiS.

Hajid, A. (2005). Orang Jawa, Jimat dan Makhluk Halus. Yogyakarta: Narasi.

Herusatoto, B. (2000). Simbolisme dalam budaya Jawa. Yogyakarta: Hanindita. Dikutip dari https://books.google.co.id/books?id=miBYAAAACAAJ

Ismail, N. (2012). Relasi Kuasa dalam Pengubahan Budaya Komunitas Negara, Muslim, Wong Sikep. Bandung: Karya Putra Darwati.

Mukodi, dan Burhanuddin, A. (2015). Pendidikan Samin Surosentiko. Yogyakarta: Lentera Kreasindo.

Rosyid, M. (2011). Kodifikasi Ajaran Samin. Yogyakarta: Kepel Press.

Rosyid, M. (2019). Makna Keris bagi Warga Samin di Kudus. Jurnal Kebudayaan Litjakdikbud Kemendikbud, 14(2).

Samiyono, D. (2010). Sedulur Sikep Struktur Sosial dan Agama Masyarakat Samin di Sukalila. Universitas Kristen Satya Wicana Salatiga.

Soerjanto, S. (2003). Masyarakat Samin Siapakah Mereka? Yogyakarta: Narasi.

Subarkah. (2017). Sedulur Sikep Menggugat Jalan Berliku Pertahankan Pegunungan Kendeng Utara. Kudus: Badan Penerbit Universitas Muria Kudus.

Suryadi, L. (1993). Regol Megal Megol: Fenomena Kosmogoni Jawa. Yogyakarta: Andi Offset.

Utomo, L. (2013). Budaya Hukum Masyarakat Samin. Universitas Sahid Jakarta. 